special view to finding the correct tune, or of the interference with signalling in a similar way. This fear is, however, somewhat imaginary, as it is doubtful whether such an enterprise would be commercially successful, and it is inconceivable that anyone should devote his energies to its realisation purely out of malicious rivalry. Even in war time, we think, it would hardly repay the labour, and, moreover, Marconi's system now promises to be of more use in peace than in war. It may be remarked, too, that syntony-especially syntony so thorough as that described by Prof. Fleming eighteen months ago, when two distinct messages were sent and received by the same transmitting and receiving wires-opens up the possibility of multiplex wireless telegraphy, which would be equivalent to a great increase in the speed of signalling.

We may finally quote some remarks made by $\mathrm{Mr}$. Marconi on his arrival in America after his success with the experiments on the Philadelphia.

"I believe," he said, "that the distance at which a wireless message may be sent depends only on the power of the sending station. I think it possible to send a message entirely around the world, to start the message

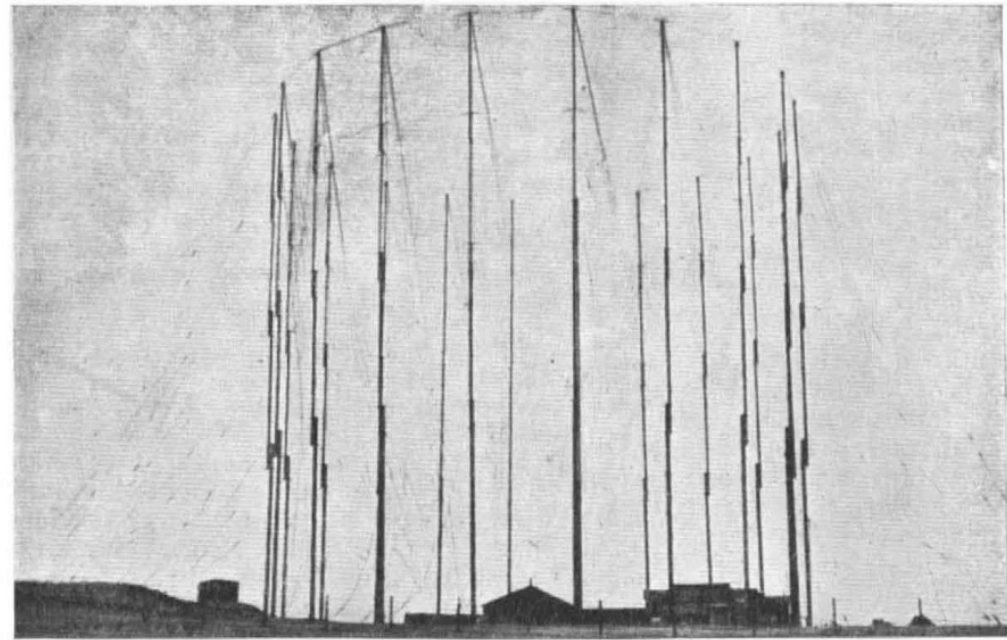

FIG. x.-View of Poldhu Station, Cornwall, whence the signals came to Marconi at St. John's. are unable to say what the Home Secretary really meant. The author, however, draws an inference which certainly is not justifiable, viz. that serious operations without anæsthetics necessarily involve the torture of animals. Whether this is so or not depends entirely upon what is meant by a serious operation and what is meant by torture, concerning neither of which is a word said. By torture we certainly do not mean mere momentary pain.

The main object of the essay is, however, threefold. In the first instance $\mathrm{Mr}$. Coleridge, presumably satisfied, from his prologue, that the legalised torture of animals by so-called vivisectors actually takes place, and that no matter what its object may be is unjustifiable, classifies all metropolitan hospitals according to their supposed connection with vivisection. He further appeals to all those who have money to give, to enrich only those hospitals printed in plain type in his list, being the ones which at the present time are entirely free from vivisection and vivisectors. The second object of the monograph seems to be to denounce as diversion of charitable funds from their legitimate object any payment from the hospitals to the medical schools attached to them. There is also in addition to this an assumption that such payments are practically for the subsidy of vivisection so-called, and a further appeal to the charitable on this count. The third object is apparently to impugn the integrity of the committee for the distribution of King Edward's Hospital Fund.

First, then, according to $\mathrm{Mr}$. Coleridge, the charitable should give only to those hospitals which at the time of their bequest are entirely free from all vivisection connections. It must be at once pointed out that this is a somewhat complicated affair, and will require very careful study upon the part of the donors, in that the staffs of hospitals change, and, further, a man of science once a vivisector is not always a vivisector. Since he does not vivisect for amusement, he does so only when he has a definite problem in his mind, and accordingly arranges a series of experiments capable of giving him a definite solution. From this it follows, as indeed the list in this pamphlet shows, eastward around the globe, and to receive it at the same station from the westward.

"I now know that the curvature of the earth does not in the least affect the waves. Many people who have reasons for hoping so have said that this would prove a fatal defect to the system, but it is not so. During the voyage I carried out a number of experiments which I had long wanted to make, but which I had never attempted before. You must pardon me for not disclosing their nature. All I can say is that they were eminently satisfactory to me."

M. S.

\section{THE METROPOLITAN HOSPITALS AND} VIVISECTION.

$\mathrm{W}^{\mathrm{E}}$ have recently received the new edition of a pamphlet entitled "The Metropolitan Hospitals and Vivisestion, a Guide for the Charitable in the Disposition of their Gifts and Bequests," by the Hon. Stephen Coleridge. The pamphlet begins with a prologue which consists of a short phrase snatched without any context from a speech delivered by the Home Secretary. Owing to the shorn character of this phrase, which stands out grotesquely framed with interpolations, we No. I 688, vOL. 65] that a hospital intimately connected with vivisectors one year may be entirely emancipated from them the next, and therefore that the terms of an anti-vivisection bequest will require alteration from year to year.

The hospitals at present free from all vivisection taint, according to the pamphlet before us, contain $45 \mathrm{I} 6$ beds ; of these 4500 beds, ethically, according to $\mathrm{Mr}$. Coleridge, eligible for the gifts of the charitable, I IO9, or practically one quarter, are devoted to lunatics or idiots. Now this fact surely should have been clearly stated, and also its corollary, viz., that should the charitable decide to support only those hospitals satisfying Mr. Coleridge's requirements for eligibility, one quarter of their subscription will be devoted to the maintenance of lunatics or imbeciles, extensive provision for which is already supplied out of the rates. Further, another fact of which the charitable, in 'Mr. Coleridge's sense, should be cognisant is, that of the remaining 3000 or so beds no less than 500 , or approximately one-eighth of the original total, are devoted to the maintenance of incurables. Twoeighths of the subscriptions of the charitable should, according to $\mathrm{Mr}$. Coleridge, go to lunatics, one-eighth to incurables. Of the remaining 2900 beds, 300 either belong to local cottage hospitals or are devoted to smallpox or other infectious diseases. The former hospitals 
will receive a large measure of support, at least in many cases, from those locally interested in them, and accommodation for infectious diseases other than small local isolation hospitals is dealt with out of the rates. From this it follows that of any subscription given according to Mr. Coleridge's lines, little more than one-half will be devoted to what the average charitable man regards as the essential function of a hospital, viz. the treatment of acute medical and surgical disease and the rendering of the unfortunate subject of it capable of returning to earn his, and very often his family's, daily bread. We think it would have been fairer and of more real help to the charitable layman whom this pamphlet pretends to guide had these considerations been clearly set forth. Let him, then, now clearly understand that had he followed Mr. Coleridge's advice during, for instance, the year 1900 , to which the figures in their entirety apply, and specifically stated that his money should go to no hospital connected with vivisection, practically half of it would have been "diverted" from the legitimate object of his charity.

To pass to a question which certainly does not possess the merit of novelty, viz. the so-called diversion of hospital funds to the medical schools attached to them, we would simply repeat what we have said before, that this is no diversion at all, no more diversion than the salary paid to a hospital gate-porter. The "managers" of the large hospitals are shrewd business men, we think more shrewd even than Mr. Coleridge, and they know full well that the efficacy of a large general hospital depends inter alia upon there being a medical school attached to it ? The clinical teachers, demonstrators and students tend the sick and teach the nurses, thus securing efficient ones ; the more purely scientific departments of the school help, each using the methods in which they are individually expert; in the elucidation of those obscure cases often demanding the technique of all. By these means the physician or surgeon becomes possessed of a knowledge of facts enabling him to adopt lines of treatment which mitigate pain, minimise the havoc of disease, and not seldom actually save life. Under the present regime these services are rendered by the medical schools gratuitously: sums granted towards the maintenance of these schools cannot be said to be diverted from the use of the sick; the sick get the full benefit of them.

If we now turn to Mr. Coleridge's impugnment of King Edward's Hospital Fund Committee, we shall arrive at some interesting deductions from the figures provided for our enlightenment which were not pointed out by the author. Mr. Coleridge has noted the fact that the allocation of the hospital fund grants per bed was greatest in the case of the hospitals possessing medical schools, and thus laboratories. In the case of the other hospitals, those which had upon their staff vivisectors received larger grants than those entirely unconnected with vivisection. Post hoc propter hoc, in other words, Lord Lister especially, and his colleagues to a less degree, have wilfully used King Edward's Hospital Fund for the purpose of endowing vivisection.

It is certainly to be assumed that King Edward's Hospital Fund was not intended for the endowment either of lunatic asylums or homes for the incurable, or local cottage hospitals, or local isolation or small-pox hospitals, which certainly ought to be provided for out of the rates. To no hospitals of this kind did the Committee, and we venture to think quite rightly, make any grant. We do not mean for one moment to infer that such institutions are not worthy of support, but the ordinary subscriber to a hospital fund does not include under that category either lunatic asylums or homes for incurable or dying patients.. If, however, we exclude the above institutions from our calculations, how are Mr. Coleridge's figures affected? The facts are these : that (taking Mr. Coleridge's remaining figures as correct) hospitals with medical schools and laboratories attached received 5 l. $8 \mathrm{~s} .9 \mathrm{~d}$.; hospitals with no medical schools, but connected in the special sense of the pamphlet with vivisectors, $4 l$. $14 s .2 d$. ; and hospitals entirely unconnected with vivisection, $5 l$. per bed. In other words, while hospitals connected with medical schools received by a small amount the most per bed, those hospitals which were entirely unconnected with vivisection received more than those to the staffs of which so-called vivisectors were attached. There is, therefore, so far as the grant per bed is concerned, no ground for Mr. Coleridge's charges.

If we look into the matter more minutely we shall see that in the details of each hospital grant there is even less reason to suspect that vivisection had anything whatever to do with it. If we compare the maximum grants per bed in the hospitals as classified by Mr. Coleridge, we shall find the largest grant of all hospitals connected with vivisection laboratories was $8 l$., or approximately $8 l$., per bed, given to Guy's, a hospital in need of funds, and one, of course, doing magnificent work. If we take two hospitals entirely unconnected with vivisection, we find in the case of the N.W. London Hospital a grant of rol. per bed, and in the case of the Royal Free Hospital a grant of $9 l$. per bed. How can it be argued, in the face of these figures, that preference was given to hospitals connected with vivisection qua vivisection? We do not wish to impugn Mr. Coleridge's motives, but the ingenious way in which he has attempted to mislead the charitable layman by the pamphlet before us is, in our opinion, in the highest degree reprehensible.

The end of this document in which truth is so distorted is devoted to a personal defamatory attack upon Lord Lister. This attack, we are pleased to see, is somewhat modified for the better since we last reviewed it ; concerning it we must refer the reader to our former article. The monograph concludes with an epilogue consisting of a repetition of an invective, couched in $\mathrm{Mr}$. Coleridge's most offensive terms, against science, and sounds like some papal bull of the middle ages anathematising that knowledge which was eventually to liberate mankind from filth, superstition, suppression and ignorance. Medical science, which perhaps has done more than any agency under Heaven to alleviate the sufferings of mankind, is ruthlessly termed "malignant." Invective is not argument, neither is calumnious opprobrium logic.

The charitable subscriber to London hospitals will see to what "diversion" his subscriptions will be subject if he follows the advice of Mr. Coleridge. It is to be hoped, and indeed to be expected, that he will give as he has done before, leaving the disbursement of his bequests to representatively elected committees of experts who, neither prompted by political motives nor influenced by mis placed and maudlin sentimentality, will assuredly allocate them to the most urgent wants of the sick.

\section{THE PROPOSED BRITISH ACADEMY.}

THE following text of the petition presented to the Privy Council by the council of the Royal Society in favour of the establishment of a British Academy appeared in the Times of February 27 :-

To The King's Most Excellent Majesty in Council. The humble petition of the President and Council of the

Showeth-

That your petitioners pray that the petition which has been presented to His Majesty in Council praying for the grant of a charter of incorporation to "The British Academy for the Promotion of Historical, Philosophical and Philological Studies" be granted.

Your petitioners are led to take this step both for the general reason that the granting of such a charter will, in their opinion, No. I688, voL. 65] 